\title{
Stress and its Relief among Undergraduate Dental Students in a Tertiary Health Care Centre in Eastern Nepal
}

\section{Sabita Paudel ${ }^{1 \star}$, Nuwadatta Subedi ${ }^{2}$ and Ashish Shrestha ${ }^{3}$}

${ }^{1}$ Department of Pharmacology, College of Medical Sciences, Bharatpur, Chitwan, Nepal

${ }^{2}$ Department of Forensic Medicine and Toxicology, College of Medical Sciences, Bharatpur, Chitwan, Nepal

${ }^{3}$ Department Community Dentistry, BP Koirala Institute of Health Sciences, Dharan, Nepal

\begin{abstract}
Background: Dentistry is associated with a number of stressors resulting to depression, anxiety, substance misuse, absenteeism, diminished work efficiency, and burnout. The study was conducted with the objectives to know the prevalence and type of stressors; their consequences stress relievers among the clinical dental students.

Methods: It is a descriptive cross-sectional qualitative study carried out using a self-administered questionnaire among the clinical dental students of a college of dental surgery of eastern Nepal. The questionnaire was adapted from the Dental Environmental Stress Questionnaire designed by Westerman et al., and was modified to include several cultural factors appropriate for Nepali students. Students were asked to assess the questionnaire items as "not stressful," "slightly stressful," "moderately stressful," and "severely stressful" on a four-point Lickert scale.
\end{abstract}

Results: When responses were divided into either stressful or not stressful, the prevalence of stress was $100 \%$. Among self-efficacy beliefs, insecurity regarding professional future, $(90.0 \%)$ atmosphere created by clinical faculty $(93.34 \%)$, difficulty to get suitable patients $(93.34 \%)$, fear of sexually transmissible diseases/AIDS/ hepatitis B while working on patients $(96.56 \%)$, need to find own patients $(88.89 \%)$ and examinations and grading procedures $(96.67 \%)$ were the common stressors in different years of study. The two most frequently mentioned consequences of stress during all years were fatigue/tiredness $(77.79 \%$ to $96.56 \%)$ and mood alteration $(69.45 \%$ to $83.33 \%)$. Listening to music was the leading stress reduction method during all academic years ( $82.76 \%$ to $86.67 \%$ ).

Conclusion: The students in all years of study had high prevalence of stress. The most frequently mentioned consequences of stress during all years were fatigue/tiredness and mood alteration. Listening to music was the leading stress reduction technique for students in all academic years. A contemporary dental school should address potential stress sources effectively, thus promoting the educational and professional well-being of dental undergraduates.

\section{Introduction}

Stress is defined as "pressure or worry caused by problems in somebody's life" [1]. The perception of stress, in fact is frequently by one's personal system of beliefs and attitudes. These self-cognitions mediate the perceived stressor and consequent student behaviour. Self-cognitions associated with control and self-efficacy tends to lower stress and distress levels resulting in improved academic performance. The term stress describes external demands (physical or mental) on an individual's physical and psychological wellbeing. Stressors associated with dentistry include time and scheduling pressures, managing uncooperative patients and the highly technical and intensive nature of work [1-4]. This resulting stress can lead to depression, anxiety, substance misuse, absenteeism, diminished work efficiency, and burnout $[3,5,6]$. The roots of this occupational stress may have their origin in the educational process as dental students experience high levels of stress during training [1,3,5-7].

Contemporary curricula require dental students to attain diverse proficiencies, including the acquisition of theoretical knowledge, clinical competencies and interpersonal skills [8]. In Nepal, the duration of the Bachelor of Dental Surgery (BDS) program is of four and half calendar years with progression examination at the end of each year, followed by one year paid rotary internship in dental colleges and is governed by the Nepal Medical Council. During the first two years of graduation, students are taught basic sciences whereas the later years are dedicated for imparting clinical education. Professional education especially medicine, dentistry, and technical education is held in very high esteem. Parents who cannot fulfil their dreams of professional education try to fulfil it through their children. In many cases, the children are forced by their parents to pursue a career that is not of their choice [2].
It has been reported that dental students express considerable stress symptoms during their training [9] and that they are more anxious than the general population [10] showing higher levels of depression, obsessive-compulsive disorders, and interpersonal sensitivity than age-matched norms [11]. Studies of dental school life, occupational pressures, health issues, alcohol use, and mortality suggest that both dental education and practice contain stress provoking elements that generally have negative effects on individual well-being [3]. Moreover, recent research suggests substantial levels of psychological distress and emotional exhaustion among first-year students at seven European dental schools.

The study was conducted with the objectives to know the prevalence of stress according to the academic year of undergraduate clinical dental students and to identify the type of stressors, consequences of stress and stress relievers among those students.

\section{Materials and Methods}

It is a descriptive cross-sectional qualitative study carried out using

*Corresponding author: Dr. Sabita Paudel, BDS, Department of Pharmacology, College of Medical Sciences, Bharatpur, Chitwan, Nepal, Tel: +977 9842039565; E-mail: sabeee56@gmail.com

Received July 05, 2013; Accepted July 24, 2013; Published July 27, 2013

Citation: Paudel S, Subedi N, Shrestha A (2013) Stress and its Relief among Undergraduate Dental Students in a Tertiary Health Care Centre in Eastern Nepal. Dentistry 3: 157. doi: 10.4172/2161-1122.1000157

Copyright: $\odot 2013$ Paudel S, et al. This is an open-access article distributed under the terms of the Creative Commons Attribution License, which permits unrestricted use, distribution, and reproduction in any medium, provided the original author and source are credited. 
a self-administered questionnaire among third year, fourth year and fifth year Bachelor of Dental Surgery (BDS) students at the College of Dental Surgery. The College of Dental Surgery in BPKIHS is one of the large and renowned colleges in Nepal. The questionnaire was adapted from the Dental Environmental Stress Questionnaire designed by Westerman et al. [1] and was modified to include several cultural factors appropriate for Nepali students. The purpose of the study was communicated well in advance to the students, and student participation in the research was voluntary. Ninety five students anonymously completed the study questionnaire in their classes prior to lectures. The overall response rate was $90.47 \%$.

It was validated by two senior academic faculty members. The questionnaire is divided into four sections. Students were asked to assess the questionnaire items as "not stressful," "slightly stressful," "moderately stressful," and "severely stressful" on a four-point Lickert scale. Section A consists of questions about characteristics of the respondents, Section B identifies potential stressors among students, Section C identifies physical and behavioral consequences of stress, and Section D deals with what students do to relieve stress.

Students willing and consenting to participate were included in the study while the students affected with psychiatric illness and/or under medication for the same were excluded. Collected data was entered in the Microsoft excel and further analyzed by SPSS 17.0.

\section{Results}

The study was conducted at the mid part of the academic year among third to fifth year students and it discussed experiences of the preceding academic year.The sample description is presented in Table 1 , indicating an overall response rate of $90.47 \%$.

When responses were divided into either stressful or not stressful, the prevalence of stress was $100 \%$ among students in all years of study. For purposes of presentation, the 30 stress provoking factors were grouped into seven categories: "Self-efficacy beliefs," "Faculty and administration," "Workload," "Patient treatment," "Clinical training," "Performance pressure," and "Others" (Tables 2-8).

Table 2 shows the stressors about self-efficacy beliefs. Insecurity regarding professional future $(90.0 \%)$ was the most common stressor among third year students. $83.33 \%$ of the $3^{\text {rd }}$ year students had fear of failing the academic year. Among the $4^{\text {th }}$ year students, fear of failing $(96.56 \%)$ was the most common stressor followed by fear of unemployment after graduation in $86.3 \%$ of the students. Fifth year students were stressed by fear of unemployment after graduation and lack of confidence about being a successful dental student equally (72.23\%).

As shown by table 3 , students of all academic years were quite stressed by the faculty and administration related issues. Atmosphere created by clinical faculty was the most stressful which was present

\begin{tabular}{|c|c|c|c|c|c|c|}
\hline \multirow{2}{*}{ Year of study } & \multirow{2}{*}{ Number } & \multicolumn{2}{|c|}{ Sex } & \multicolumn{2}{|c|}{ Marital status } & \multirow{2}{*}{ Response rate } \\
\hline & & Males & Females & Unmarried & Married & \\
\hline $3^{\text {rd }}$ & 30 & 19 & 11 & 30 & 0 & $85.71 \%$ \\
\hline $4^{\text {th }}$ & 29 & 12 & 17 & 27 & 2 & $96.67 \%$ \\
\hline $5^{\text {th }}$ & 36 & 20 & 16 & 35 & 1 & $90.0 \%$ \\
\hline Total (\%) & $95(100 \%)$ & $51(53.68 \%)$ & $43(46.3 \%)$ & $92(96.8 \%)$ & $3(3.15 \%)$ & $90.47 \%$ \\
\hline
\end{tabular}

Table 1: Demographics of dental students participating in the study.

\begin{tabular}{|c|c|c|}
\hline \multirow{2}{*}{ Stressors } & \multicolumn{2}{|c|}{ Number (\%) } \\
\cline { 2 - 3 } & Third year & Fourth year \\
\hline Fear of failing & $25(83.33)$ & $28(96.56)$ \\
\hline Fear of unemployment after graduation & $23(76.67)$ & $25(86.3)$ \\
\hline Lack of confidence about being a successful dental student & $27(90.0)$ & $23(79.32)$ \\
\hline
\end{tabular}

Table 2: Self-efficacy beliefs.

\begin{tabular}{|c|c|c|}
\hline \multicolumn{1}{|c|}{ Stressors } & \multicolumn{2}{|c|}{ Number (\%) } \\
\cline { 2 - 3 } & Third year & Fourth year \\
\hline Rules and regulations of the faculty & $27(90.0)$ & $25(86.3)$ \\
\hline Attitudes of faculty toward women dental students & $20(66.67)$ & $20(69.0)$ \\
\hline Inconsistency of feedback regarding work among different faculties & $23(76.67)$ & $24(77.79)$ \\
\hline Atmosphere created by clinical faculty & $28(93.75)$ & $28(72.23)$ \\
\hline
\end{tabular}

Table 3: Faculty and administration.

\begin{tabular}{|c|c|c|}
\hline \multicolumn{1}{|c|}{ Stressors } & \multicolumn{2}{|c|}{ Number (\%) } \\
\cline { 2 - 3 } & Third year & Fourth year \\
\hline Lack of time for relaxation & $23(76.67)$ & $27(93.2)$ \\
\hline Amount of assigned class work & $21(70.0)$ & $26(89.66)$ \\
\hline Difficulty with class work & $21(70.0)$ & $24(66.67)$ \\
\hline Receiving criticism about work & $27(69.45)$ & $25(75)$ \\
\hline Lack of time to do assigned school work & $22(73.34)$ & $23(79.79)$ \\
\hline
\end{tabular}

Table 4: Workload. 
in $93.34 \%$ among the third year students, $96.56 \%$ in fourth year and $88.89 \%$ in the final year students. When stressors related to the workload were assessed, receiving criticism about work was the most common one in the $3^{\text {rd }}$ year students $(90.0 \%)$, lack of time for relaxation in the fourth years $(93.2 \%)$ and difficulty with class work and lack of time to do assigned school work equally in the fifth year students (77.79\%) as represented in Table 4.

Table 5 shows the stressors regarding patient treatment. Difficulty to get suitable patients (93.34\%) was the most common stressor among the third year students. Fourth year students were most feared of sexually transmissible disease/AIDS/ hepatitis B while working on patients $(96.56 \%)$. Need to find own patients $(88.89 \%)$ were the most common stressor among the fifth year students. As depicted in table 6 , clinical training problems like difficulty in learning clinical procedures and precision manual skills required in preclinical and laboratory work was most prevalent among the third year students (86.67\%) and it was in decreasing order up to fifth year students $(69.45 \%)$.

When performance pressure was considered, third year students were most stressed by examinations and grading procedures $(96.67 \%)$. $88.89 \%$ of the fifth year students had fear of being unable to catch up if left behind (Table 7). Financial sources problem was also one of the common stressors which were present in $86.67 \%$ of the third year and $89.66 \%$ of the fourth year students. $86.67 \%$ of the third year and $89.66 \%$ of the fourth year students were stressed by the lack of conductive study environment at home/living quarters/hostel. $86.3 \%$ of the fourth year, $83.33 \%$ of the third year and $72.23 \%$ of the fifth year students were stressed by the system of compulsory attendance in the college (Table $8)$.

The consequences of stress among students are shown in Table 9. The two most frequently mentioned consequences of stress during all years (not in order of frequency) were fatigue/tiredness $(77.79 \%$ to $96.56 \%$ ) and mood alteration (69.45\% to $83.33 \%)$. Other frequently mentioned consequences were sleep disturbance (58.34\% to $63.34 \%$ ), back pain $(40.0 \%$ to $69.45 \%)$, sleep disturbance $(58.34 \%$ to $69.34 \%)$ and headache $(44.83 \%$ to $61.12 \%)$. The less common consequences were abdominal disturbance ( $13.34 \%$ to $25.0 \%$ ), oral ulcers $(13.34 \%$ to $31.04 \%)$ and flu/common cold (2.78\% to $13.34 \%)$.

Table 10 shows the various methods of stress reduction among the students. Listening to music was the leading stress reduction method during all academic years $(82.76 \%$ to $86.67 \%)$. Sleeping $(50.0 \%$ to $72.42 \%$ ), talking with friends (55.56\% to $68.97 \%$ ), and watching movies at home or at the cinema ( $44.45 \%$ to $70.00 \%)$, family ( $27.59 \%$ to $50.0 \%)$ were the commonly used ways of reducing stress for all academic years. Meditation was also a common method in all the academic years (20.69\% to $33.34 \%) .31 .04 \%$ of the $4^{\text {th }}$ year students responded that they drank alcohol for stress relief. The same was adopted by $27.78 \%$ of the fifth year and $20.0 \%$ students of the third year. Professional help of doctors, psychiatrists and counselor was taken by only a few of students

\begin{tabular}{|c|c|c|}
\hline \multicolumn{1}{|c|}{ Stressors } & \multicolumn{2}{|c|}{ Number (\%) } \\
\cline { 2 - 3 } & Third year & Fourth year \\
\hline Responsibilities for comprehensive patient care & $22(73.34)$ & $23(79.32)$ \\
\hline Patients arriving late or not showing up for appointment & $20(66.67)$ & $24(82.75)$ \\
\hline Working on patients with dirty mouths & $25(83.33)$ & $25(86.3)$ \\
\hline Need to find own patients & $25(83.33)$ & $27(93.2)$ \\
\hline Difficulty to get suitable patients & $28(93.34)$ & $26(89.66)$ \\
\hline Lack of cooperation by patients & $19(63.34)$ & $24(82.12)$ \\
\hline Fear of sexually transmissible disease/AIDS/ hepatitis B while working on patients & $23(76.67)$ & $2.56)$ \\
\hline
\end{tabular}

Table 5: Patient treatment.

\begin{tabular}{|c|c|c|c|}
\hline \multirow{2}{*}{ Stressors } & \multicolumn{3}{|c|}{ Number (\%) } \\
\hline & Third year & Fourth year & Fifth year \\
\hline Difficulty in learning clinical procedures & $26(86.67)$ & $25(86.3)$ & $25(69.45)$ \\
\hline Difficulty in learning precision manual skills required in preclinical and laboratory work & $26(86.67)$ & $23(79.32)$ & $25(69.45)$ \\
\hline
\end{tabular}

Table 6: Clinical training.

\begin{tabular}{|c|c|c|}
\hline \multicolumn{1}{|c|}{ Stressors } & \multicolumn{2}{|c|}{ Number (\%) } \\
\cline { 2 - 3 } & Third year & Fourth year \\
\hline Eear of being unable to catch up if left behind & $29(96.67)$ & $26(89.66)$ \\
\hline
\end{tabular}

Table 7: Performance pressure.

\begin{tabular}{|c|c|c|}
\hline \multicolumn{1}{|c|}{ Stressors } & \multicolumn{2}{|c|}{ Number (\%) } \\
\cline { 2 - 3 } & Third year & Fourth year \\
\hline Financial sources & $26(86.67)$ & $26(89.66)$ \\
\hline Lack of home atmosphere in the living quarters & $25(83.33)$ & $25(86.3)$ \\
\hline Physical health problems & $22(73.34)$ & $20(69.0)$ \\
\hline Discrimination due to class, status or ethnic group & $25(83.33)$ & $19(65.52)$ \\
\hline Lack of conductive study environment at home/iving quarters/hostel & $15(50.0)$ & $24(66.67)$ \\
\hline
\end{tabular}

Table 8: Other stressors. 


\begin{tabular}{|c|c|c|c|}
\hline \multirow{2}{*}{ Consequences } & \multicolumn{3}{|c|}{$\mathbf{N}(\%)$} \\
\cline { 2 - 4 } & Third year & Fourth year & Fifth year \\
\hline Fatigue/tiredness & $25(83.33)$ & $28(96.56)$ & $28(77.79)$ \\
\hline Mood alteration & $25(83.33)$ & $12(41.38)$ & $25(69.45)$ \\
\hline Eye strain & $3(10.0)$ & $9(31.04)$ & $13(36.12)$ \\
\hline Back pain & $12(40.0)$ & $18(62.07)$ & $25(69.45)$ \\
\hline Headache & $14(46.67)$ & $13(44.83)$ & $22(61.12)$ \\
\hline Sleep disturbance & $19(63.34)$ & $17(58.63)$ & $21(58.34)$ \\
\hline Abdominal disturbance & $4(13.34)$ & $6(20.69)$ & $9(25.0)$ \\
\hline Flu/common cold & $4(13.34)$ & $1(3.45)$ & $1(2.78)$ \\
\hline Oral ulcers & $4(13.34)$ & $9(31.04)$ & $6(16.67)$ \\
\hline Affect performance & $17(56.67)$ & $9(31.04)$ & $12(33.34)$ \\
\hline
\end{tabular}

Table 9: Consequences of stress.

\begin{tabular}{|c|c|c|c|}
\hline \multirow{2}{*}{ Stress reduction methods } & \multicolumn{3}{|c|}{ N (\%) } \\
\cline { 2 - 4 } & Third year & Fourth year & Fifth year \\
\hline Listening to music & $26(86.67)$ & $24(82.76)$ & $31(86.12)$ \\
\hline Playing a musical instrument & $3(10.0))$ & $8(27.59)$ & $13(36.12)$ \\
\hline Read magazines or books & $7(23.34)$ & $8(27.59)$ & $14(38.89)$ \\
\hline Physical activity & $12(40.00)$ & $8(27.59)$ & $12(33.34)$ \\
\hline Meditation & $8(26.67)$ & $6(20.69)$ & $12(33.34)$ \\
\hline Watching movies at home or at the cinema & $21(70.00)$ & $19(65.52)$ & $16(44.45)$ \\
\hline Smoking cigarettes & $4(13.34)$ & $5(17.25)$ & $9(25.0)$ \\
\hline Drinking alcohol & $6(20.00)$ & $9(31.04)$ & $10(27.78)$ \\
\hline Sleeping & $21(70.00)$ & $21(72.42)$ & $18(50.0)$ \\
\hline Spouse/girlfriend/boyfriend & $7(23.34)$ & $10(34.49)$ & $7(19.45)$ \\
\hline Friends & $19(63.34)$ & $20(68.97)$ & $20(55.56)$ \\
\hline Family & $15(50.0)$ & $8(27.59)$ & $13(36.12)$ \\
\hline Shopping/window shopping & $8(26.67)$ & $7(24.14)$ & $7(19.45)$ \\
\hline Lecturers/mentors/academic advisors & $0(0.00)$ & $2(6.9)$ & $1(2.78)$ \\
\hline Professional help: doctor, psychiatrist, & $1(3.34)$ & $3(10.35)$ & $1(2.78)$ \\
\hline counselor & $4(13.34)$ & $3(10.34)$ & $4(11.12)$ \\
\hline Others & &
\end{tabular}

Table 10: Methods of stress reduction among dental students.

(2.78\% to $10.35 \%)$. The other methods as mentioned by some of the students were swimming, using facebook, masturbation etc.

\section{Discussion}

The prevalence of stress was $100 \%$ for all years of study. Only the clinical students were included in our study to achieve greater extent of uniformity. The results of this study support the existing evidence in the literature, indicating that dental students are subject to numerous work-related and academic stressors that may adversely affect their physical and psychological health $[2,6,12-15]$.

The primary sources of stress in the dental students were self efficacy beliefs, assigned workload, and performance pressure. This is consistent with findings of other studies $[2,6,12,14,15]$. The causes of stress varied by year of study with some overlap. Insecurity regarding professional future was the most prevalent among the third year students and it gradually decreased through the fourth to the fifth year. This indicates that with progress in academic years, students gain confidence of successful future. The similar trend was with rules and regulations of the faculty, atmosphere created by clinical faculty and receiving criticism about works. This may be associated with the postings in medical wards and the clinical dentistry postings at the same time.

The students in the third year of studies were the most affected by the acquisition of manual skills in preclinical and laboratory work.
This is the year students are introduced to clinical procedures. They may face difficulties in learning clinical procedures both theoretically and practically. These findings indicate that third-year students may be overloaded by the high academic demands of their year of study, whereas the absence of early clinical exposure may be triggering anticipatory stress reactions in regard to the upcoming encounter with clinical training.

The stressors of faculty related issues like rules and regulations of the faculty, atmosphere created by clinical faculty, inconsistency of feedback regarding work among different faculties were prevalent commonly among the students of all the academic years. The results are consistent with Malaysian study by Ahmad et al. [12]. But in contrast from a study from Greece by Polychronopoulou and Divaris [15]. It is possible that the informal nature of social relationships in Mediterranean nations such as Greece helps students feel comfortable interacting with faculty and staff in dental school environment. Whereas in the context of Asian countries where there is formal student- faculty relationship, students can't express their feelings properly. They have to adhere to the strict disciplinary rules and regulations in the college. This might have contributed to the greater prevalence of stress regarding the issues.

Items related to patient management were the most mentioned stressors for the fourth and fifth year students which includes responsibilities for comprehensive patient care, patients arriving late or not showing up for appointment, need to find own patients and lack of cooperation by patients. Comparing fourth and fifth year students, problems with patient management were a greater cause of stress among fourth year students than fifth year students. The spike in stress levels among fourth year students points to the stress the students face when entering the pure dental clinical setting. Students may find difficulty in finding their own patients and applying their clinical skills to treating these patients at an early stage.

The large quantity of difficult material students are required to master may cause them to feel inadequate for the task, which in turn results in the students becoming fearful about being able to complete their schedule and examination requirements on time. Dental colleges put a heavy emphasis on clinical sciences and focus on producing graduates with competent clinical skills [16]. Some student's fear they will not be able to catch up if they fall behind or failing a course or the year. Coming towards the end of the course, students fear more about inability to catching up if they fail as they have to repeat six more months if they fail in the fifth year.

The most frequently mentioned consequences of stress in all classes of students were fatigue/tiredness, mood alteration, sleep disturbance, effect on performance and headache. Listening to music was the leading stress reduction technique for students in all academic years. Watching movies at home or at the cinema, sleeping, talking to friends and family members and physical activities were other commonly adopted methods of stress reduction. A study by Muirhead and Locker [17] found students who received more social support tended to have less stress; such social support can come from teachers, parents or other students. Sugiura et al. [18] concluded the level of stress was lower among students who engaged in regular exercise, which allowed them to develop good human relationships. Music and movies were also popular remedies for stress. Music and movies are forms of entertainment which are believed to nourish and soothe the mind, thus enabling students to relax. As shown in a study done by White [19] suggested listening to relaxing music helped to reduce heart rates, respiratory rates, and anxiety scores. 


\section{Recommendations}

The results of this study suggest that a variety of changes need to be considered in the colleges of Dental Surgery in Nepal. Students wishing to study dentistry should be exposed to the nature of the profession and the study environment prior to applying to this program. We also recommend an entrance interview to evaluate the candidate's interest and suitability for the course. Dental colleges should collaborate with educational experts in designing and developing a curriculum structure which is more student-orientated, aimed at enhancing the students' psychological well-being whilst maintaining a focus on academic and clinical performance and producing graduates with a positive professional attitude. The student teacher relationship should be reformed to be more friendly so that the students won't fear with them and can share their feelings more comfortably. Teachers should understand their students and encourage them to share their problems. The students who are poor in academics and clinical skills should be given more time to improve them rather not humiliating them.

A change that we recommend is that unit requirements (quotas) may need to be eliminated. The successful completion of quotas seems to be a significant source of stress. For the completion of the quota, the students may have to rush to find their own patients, which not only increases the stress but also they have inadequate time to study and relax.

A stress reduction program could be implemented. Such programs for dental students as including specific courses, stress-reduction sessions, introduction to behavioural sciences and faculty incorporated advising systems foster coping behaviours that are useful on a daily basis, as well as preventative measures to reduce chronic stress effects.

\section{Conclusion}

The primary sources of stress as perceived by 95 clinical dental students at College of Dental Surgery, BP Koirala Institute of Health Sciences were their self-efficacy beliefs, faculty and administration, performance pressure and assigned workload. Moreover, students in different years of study perceived different sources of stress. The students in the third year of studies were the most affected by the acquisition of manual skills in preclinical and laboratory works. Items related to patient management were the most mentioned stressors for the fourth and fifth year students which includes responsibilities for comprehensive patient care, patients arriving late or not showing up for appointment, need to find own patients and lack of cooperation by patients.

The most frequently mentioned consequences of stress during all years were fatigue/tiredness and mood alteration. Listening to music was the leading stress reduction technique for students in all academic years. Although some of the high-rated stressors appear to be inherent in professional education and prevalent to diverse dental educational settings, a contemporary dental school should address potential stress sources effectively, thus promoting the educational and professional well-being of dental undergraduates.

\section{Limitations}

To determine whether the illustrated stressors are characteristic for dental students or if they are global burdens for students at different stages of their educations in general, comparison of the dental students with students from other branches of study can be done. Furthermore reference values from the analyzed students before their beginning of the studies if available could have been useful to determine whether illustrated stressors have probably always existed or they have really developed only during the studies.

\section{References}

1. Westerman GH, Grandy TG, Ocanto RA, Erskine CG (1993) Perceived sources of stress in the dental school environment. J Dent Educ 57: 225-231.

2. Acharya S (2003) Factors affecting stress among Indian dental students. J Dent Educ 67: 1140-1148.

3. Heath JR, Macfarlane TV, Umar MS (1999) Perceived sources of stress in dental students. Dent Update 26: 94-98, 100.

4. Rajab LD (2001) Perceived sources of stress among dental students at the University of Jordan. J Dent Educ 65: 232-241.

5. Freeman R, Main JR, Burke FJ (1995) Occupational stress and dentistry: theory and practice. Part I. Recognition. Br Dent J 178: 214-217.

6. Naidu RS, Adams JS, Simeon D, Persad S (2002) Sources of stress and psychological disturbance among dental students in the West Indies. J Dent Educ 66: 1021-1030

7. Newton JT, Baghaienaini F, Goodwin SR, Invest J, Lubbock M, et al. (1994) Stress in dental school: a survey of students. Dent Update 21: 162-164.

8. Kumar S, Dagli RJ, Mathur A, Jain M, Prabu D, et al. (2009) Perceived sources of stress amongst Indian dental students. Eur J Dent Educ 13: 39-45.

9. Newbury-Birch D, Lowry RJ, Kamali F (2002) The changing patterns of drinking illicit drug use, stress, anxiety and depression in dental students in a UK dental school: a longitudinal study. Br Dent J 192: 646-649.

10. Piazza-Waggoner CA, Cohen LL, Kohli K, Taylor BK (2003) Stress management for dental students performing their first pediatric restorative procedure. J Dent Educ 67: 542-548.

11. Sanders AE, Lushington K (1999) Sources of stress for Australian denta students. J Dent Educ 63: 688-697.

12. Ahmad MS, Md Yusoff MM, Abdul Razak I (2011) Stress and its relief among undergraduate dental students in Malaysia. Southeast Asian J Trop Med Public Health 42: 996-1004.

13. Sanders AE, Lushington K (2002) Effect of perceived stress on student performance in dental school. J Dent Educ 66: 75-81.

14. Tangade PS, Mathur A, Gupta R, Chaudhary S (2011) Assessment of Stress Level among Dental School Students: An Indian Outlook. Dent Res J (Isfahan) 8: 95-101.

15. Polychronopoulou A, Divaris K (2005) Perceived sources of stress among Greek dental students. J Dent Educ 69: 687-692.

16. Divaris K, Barlow PJ, Chendea SA, Cheong WS, Dounis A, et al. (2008) The academic environment: the students' perspective. Eur J Dent Educ 1: 120-130.

17. Muirhead V, Locker D (2008) Canadian dental students' perceptions of stress and social support. Eur J Dent Educ 12: 144-148.

18. Sugiura G, Shinada K, Kawaguchi $Y$ (2005) Psychological well-being and perceptions of stress amongst Japanese dental students. Eur J Dent Educ 9: $17-25$.

19. White JM (1992) Music therapy: an intervention to reduce anxiety in the myocardial infarction patient. Clin Nurse Spec 6: 58-63. 